研究

\title{
無限層 $\mathrm{Sr}_{1-\mathrm{x}} \mathrm{La}_{\mathbf{x}} \mathrm{CuO}_{2}$ の高圧合成と超伝導性
}

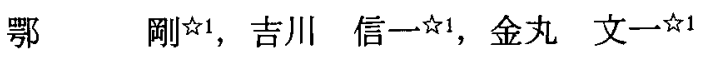 \\ 宮本 欽生约, 吉岡 秀樹放2, 元山 宗之放2
}

的大阪大学産業科学研究所, $\mathbf{T} 567$ 茨木市美楆 $r$ 丘 8 の 1 .

的 兵莗県立工業技術センター, 宁654 神戸市須磨区行平町3-1-12.

\section{High Pressure Synthesis of Infinite-layered $\mathrm{Sr}_{1-x} \mathrm{La}_{\mathbf{x}} \mathrm{CuO}_{2}$ and Its Superconductivity}

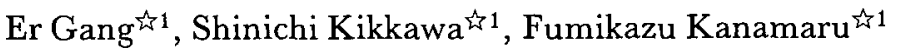

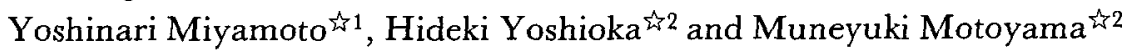 \\ A1 ISIR, Osaka University, Ibaraki, Osaka 567. \\ it 2 Hyogo Prefectural Institute of Industrial Research, Suma, Kobe 654 .
}

Received January 16, 1992

A new superconductor $\mathrm{Sr}_{1-x} \mathrm{La}_{x} \mathrm{CuO}_{2}$ having an infinite-layer structure was prepared in a reductive atmosphere applying high pressure synthesis. Its solid solution limit was around $X=0.12$. The Tc (onset) value was $43 \mathrm{~K}$ independently on $X$ and the volume fraction of the superconductor showed a maximum at $X=0.10$. Positive value was observed on a Hall effect measurement on the sample with $X=0.10$ in a temperature range above $77 \mathrm{~K}$.

\section{1 緒言}

銅の周りに酸索が平面四配位したCu0 2 導電面間にア ルカリ土類金属がはさまれた、いわゆる無限層構造は 椂々な銅酸化物系高温超伝導体の究極の結晶構造と考 えられる。つまりこれらの超伝導体ではCUO ${ }_{2}$ 導電面と その間に導電面に対してホール叉は雪子を供給する複 雑な構造をるつ修飾首からなっていた。しかし無限層 構造では修㹮層に対応するものは金属イオンだけで酸 索を含まず極めて単純な結晶構造である。Siegristら および山根らは $\mathrm{Ca}_{1-\pi} \mathrm{Sr}_{\mathbf{x}} \mathrm{CuO}_{2}(\mathrm{X}=0.14$ および0.09)の極 めて限られた組成で無限層構造を作れる事を報告した 1, 2). 高野らは6万気圧の高圧下で $\mathrm{SrCuO}_{2}$ が無限層構造 に相転移する事を報告しだ”．その当時から無限層構 造に対してホールをドープして超伝導化する可能性が 指摘されていたが成功していなかった。最近高野らは
Sr-Cu-0系で高圧合成した試料中に、Tcが60～100Kの超 伝導体が存在する事を示しだ。しかし生成物は単一 相ではなく超伝導性がどのような結晶構造の物貿によ ろのかも明かでない。我々は以前にYBa $\mathrm{Y}_{2} \mathrm{Cu}_{4} \mathrm{O}_{8}$ に高压下 でCaをドープしようとした時にみられたTc こ20Kの無限 層構造ではないかと考えられる末知相”の存在を見い だした。これを単相化しようとした際に、単相化がよ り容易に思われた $\mathrm{SrCuO}_{2}$ への希土類ドープを高压下で 試みた。電子ドープするためには導電面上のCu-0距離 が長い程電子ドープされ易いと考元 $\mathrm{La}^{3+}$ のドーブを行 った.ごく最近になって我々とは独立にSmithらがやは り高压下で $\mathrm{S}_{1-\mathrm{x}} \mathrm{Nd}_{\mathrm{x}} \mathrm{CuO}_{2}$ を合成してTc=40Kの超伝導性 を報告し、キャリヤーが承子である可能性を指摘した

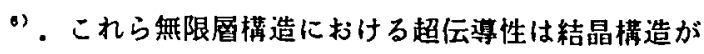
単純で超伝導発現の機構が考元易いのみならず、導奄 
面の間隔が短くフラックスが互いに相互作用してJcが 高い可能性む考えられ興味深い7. 本研究では高圧下

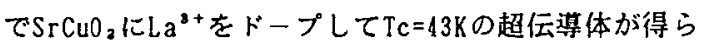
れたので、合成方法と测定結果について中間的な報告 をする゙。

\section{2 武料および実験方法}

所定のモル比に混合した $\mathrm{SrCO}_{3} 、 \mathrm{La}_{2} \mathrm{O}_{2} 、 \mathrm{Cu} 0$ の混合物 を $950^{\circ} \mathrm{C} て ゙ 30 〜 48$ 時間仮焼して常压相のSrCuO $、 \mathrm{La}_{2} \mathrm{O}_{2}$ 、 Cu0の混合物とした。これを正六面体型高圧力発生装置 を用いて、3〜 5万気圧、950 $1000^{\circ} \mathrm{C}$ の高温高圧条件下 で〜2時間処理して生成物を得た。粉末X線回折はリガ クRINTシステムによって测定し、 $32^{\circ}<2 \theta(\mathrm{Cu}-\mathrm{K} \alpha)<$ $80^{\circ}$ の10本の回折線を用いて最小自乘法により格子定 数を精密化した．電気抵抗は銀ぺーストを用いた四端 子法で測定した。磁化率はホクサンHSSM-1000型SQUID で測定した。含有酸素量は堀場EMGA-650によって定量 した。XPSはアルバックーファイESCA MT-5500で测定し た。

\section{3 実験結果及び考察}

高温高压処理中に原料中の含有酸菜量が变化しない ように原料粉を金チューブ中に密封して処理したとこ ろ、 $\mathrm{SrCuO}_{2}$ の無限層への相転移はみられたが $\mathrm{La}{ }^{3+}$ のド ープはおこらなかった。 $\mathrm{La}^{3+を ト ゙ ー フ ゚ す る に は C u+を ~}$ 少し嗹元する必要があるのではないかと考え、金于二 ーブを使わずに原料粉を直接BN容器に入れて高温高压 処理を行った。生成物の表面は退元が進みすぎて $\mathrm{Cu}_{2} \mathrm{O}$ によると思われる赤褐色になっていたが、内部は黒色 で図1のX線回折図のようにごく少量の不純物を含むる

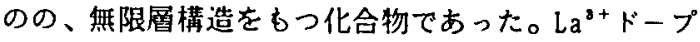
量の增加とともに線回折線のピーク位置にシフトがみ られ、X=0.15ではすでにかなり不純物がみられた。正 方晶の格子定数cは图 2 に示すように、Sr ${ }^{2+}$ に比べてイ オン半径が小さなLa"のドープ量が增すとともに直線 的に減少した。しかし軸長はドープ量とともに伸びて、 $\mathrm{La}^{3+} ト ゙ ー フ ゚ に よ っ て \mathrm{CuO}_{2}$ 導電面に電子がドープされて いる可能性を示唆した。X=0.15では既にVegard則から ズレており、また粉末線回折に不純物がみられた事か らも固溶限界は $X=0.12$ 付近と考えられる。含有酸素量

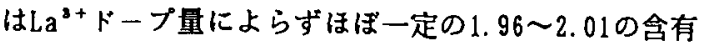
量であった。四端子法で電気抵抗を測定すると図 3 の ようにXの值によらずほぼ一定のTc (onset) $=43 \mathrm{~K} の$ 超伝 導性がみられた。 $X=0.1$ の時に常伝導の抵抗值および
Tcともに最も小さかった。0.200の残留磁場中での磁 化率测定でも $\mathrm{c}$ (onset) $=43 \mathrm{~K}$ のマイスナー効果による反 礅性がみられ、マイスナー分率はX=0.1の場合に最大で 約 $30 \%$ であった。残留磁場中ではヒステリシスが見ら れなかったが、1000eの磁場中では図4のようにヒス テリシスがみられた。しかし残留磁場中での测定と同 様にTc (onset) $=43 K$ であり、X=0.1でマイスナー分率が 最大で約 $10 \%$ と反磁性の引きが最も強かった。 $X=0.1 の$ 試料について300Kまでの常伝尊状態における熱起電力 は一 $0.7 \mu \mathrm{V} /$ と 、他の高温超伝導体における正の值の 絶対値に比べて二桁小さい負の值を示した”。しかし液 体空素温度以上 $300 \mathrm{~K}$ まで温度域におけるホール保数 は図 5 のように正の值であった。ホール係数の符号は ドーピングの種類とは対闷阅係がなく、フェルミ面の 形によって決まることが明らかになってきているい。 電子ドープ系である $\mathrm{Nd}_{2-\mathrm{x}} \mathrm{Ce}_{\mathrm{x}} \mathrm{CuO}_{4}$ でもホール係数は正 の符号をるつ”。無限層構造をむつ $\mathrm{CaCuO}_{2}$ にいての バンド計算結果 ${ }^{22}$ によるとフェルミ面の形状はNd2-x $\mathrm{Ce}_{x} \mathrm{Cu} 0$ 、の場合ともよく似ており、やはりホール保数の 符号は正となる可能性が高い。高圧合成したままの焼 結体についてエッチングしながらXPSの測定を行った。 Cu $2 \mathrm{P}_{2 / 2} 、 2 \mathrm{P}_{1 / 2}$ ピークともにLa+をドープしてる大き な変化は見られず、まだ明確なフェルミエッジも测定 されなかった。

Smithらによって報告された $\mathrm{Sr}_{1-\mathrm{x}} \mathrm{Nd}_{\mathrm{x}} \mathrm{CuO}_{2}(0.14<\mathrm{X}<$ 0. 16)ではTc(onset) $=34 \sim 40 \mathrm{~K}$ 、格子定数 $a=3.942 \sim$

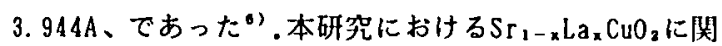
する実験結果と此較すると、無限層構造ではa軸長が長 い程Tcが高いのではないかと予測された。そこで(Sr。

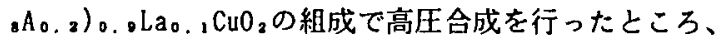
$\mathrm{A}=\mathrm{Ca}$ の時には無限層構造のほぼ単一相が得られた。し

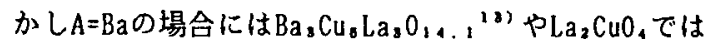
ないかと思われる相がかなりの量混在した生成物が得 られた。Srに比べてイオン半径の小さなCaを置換した 試料では格子定数a=3.934Aと縮み、Tc (onset) $=38.5 K$ K 低下した。Ba置換の場合る単一相でないためか、a= 3. 943AとSrだけの場合に比べて縮み、Tc (onset) $=41 \mathrm{~K} て ゙$ あった。Ca置換体の実験結果および従来の報告値との 比較加ら考えて無限層構造においてTcを向上させるた めには軸長を伸ばす必要があるように思われる。

\section{謝辞}

酸卖量の定量は虽場製作所分析センターの岡山順二 氏に、ホール係数および熱起電力の測定は名古屋大学 
理学部の佐藤正伐氏にお願いした。研究費の一部分は 科学研究費重点領域研究「知的材料設計亡新素材の舦 生」より支出された。記して謝意を表したい。

\section{文献}

1) T. Siegrist. S. M. Zahurak, D. W. Murphy and R. S. Roth, Nature 334 (1988) 231.

2）山根久典、宮崎譲、平井敏雄：日本セラミックス 協会誌、97（1989） 143.

3) M. Takano, Y. Takeda, H. Okada, M. Miyamoto and K. Kusaka, Physica C 159 (1989) 375.

4) Z. Hiroi, M. Takano, M. Azuma, Y. Takeda and Y. Bando, Physica C 印刷中.

5) 䟝剛：大阪大学大学院理学研究科修士諭文 (1991).

6) M. G. Smith, A. Manthiram, J. Zhou,
J. B. Goodenough and J. T. Markert, Nature, 351 (1991) 549.

7) K.Kitazawa, "Ceramics:Toward the 21st Century" ed by N. Soga and A. Kato, The Ceramic Society of Japan. Tokyo (1991). p279.

8) C. Ehr, Y. Miyamoto, F. Kanamaru and S. Kikkawa, Physica C, 181 (1991) 206.

9) 佐藤正伐 : 私信

10）兵田期昭：日本物理学会誌、16（1991） 368.

11) Z. Z. Wang, T.R. Chien, N. P. Ong, J. M. Tarascon and E. Wang, Phys. Rev. B43 (1991) 3020.

12) D. Singh, W. E. Pickett and H. Krakauer. Physica C 162/161 (1989) 1431.

13) L. Er-Rakho, C.Michel, J. Provost and B. Raveau, J. Sol id State Chem., 37 (1981) 151.

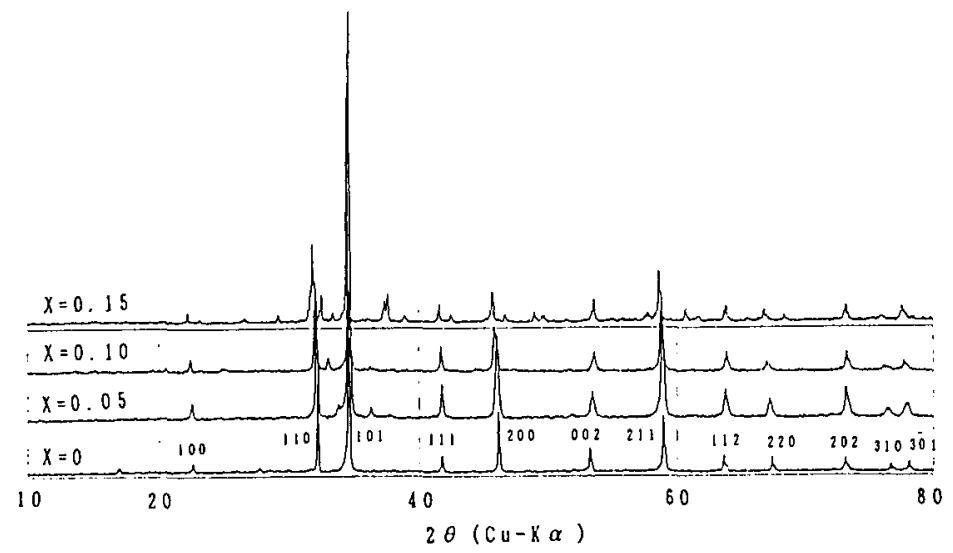

Fig. 1 X-ray diffraction pattern of $\mathrm{Sr}_{1-x} \mathrm{La}_{x} \mathrm{CuO}_{2} \quad(0 \leqq X \leqq 0.15)$.
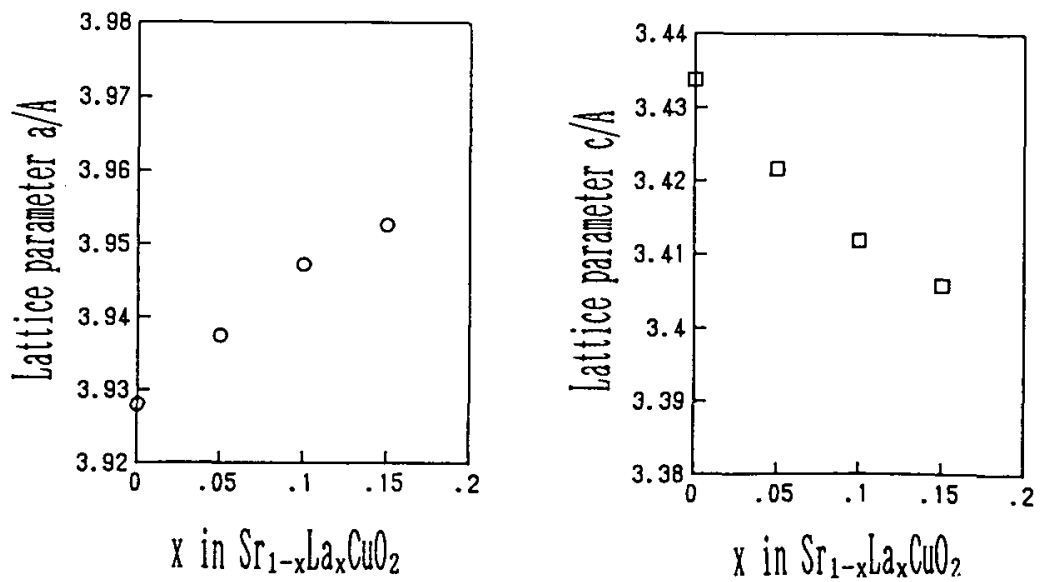

Fig. 2 Variation of lattice parameters a and $c$ with the amount of $X$. 

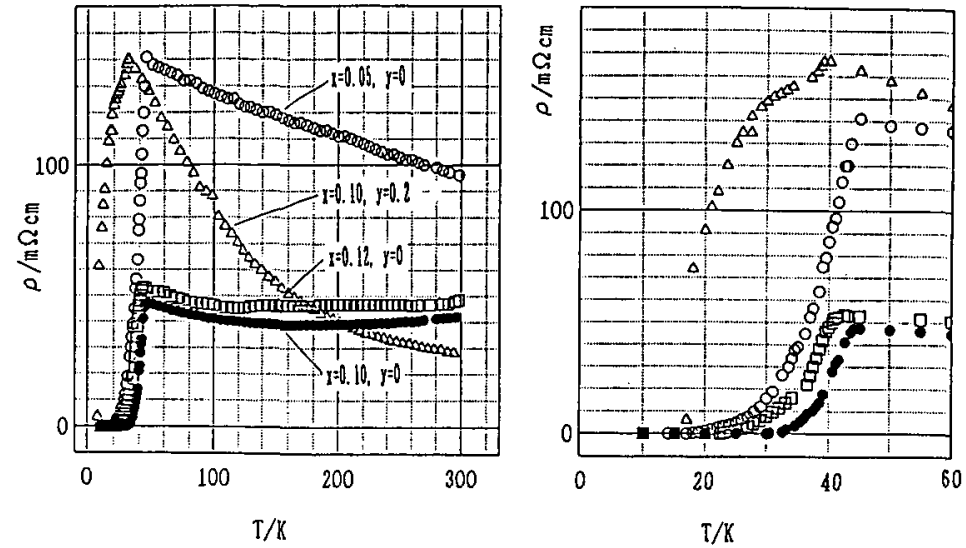

Fig. 3 Temperature dependence of electrical resistivity of $\left(\mathrm{Sr}_{1-y} \mathrm{Ca}_{y}\right)_{1-x} \mathrm{la}_{\mathbf{x}} \mathrm{CuO}_{2}$.
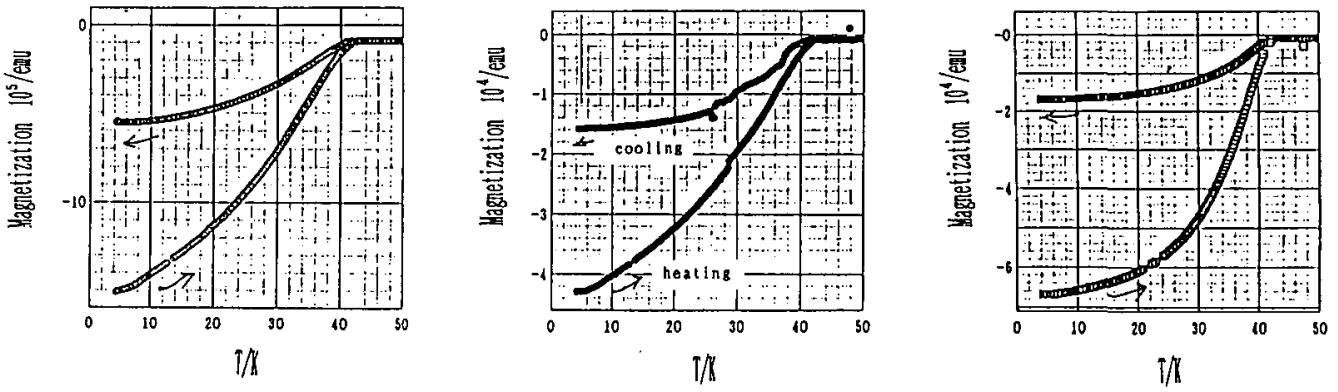

Fig. 4 Magnetization of $\mathrm{Sr}_{1-x} \mathrm{La}_{\mathbf{x}} \mathrm{CuO}_{2}$ under magnetic field of $100 \mathrm{0e}$. Both $\mathrm{X}$-value and volume $\mathrm{fraction}$ in field cooling at $4.2 \mathrm{~K}$ for the respective figures are $X=0.05,5 \% ; X=0.10,10 \% ; X=0.12,6 \%$ from left to right side.

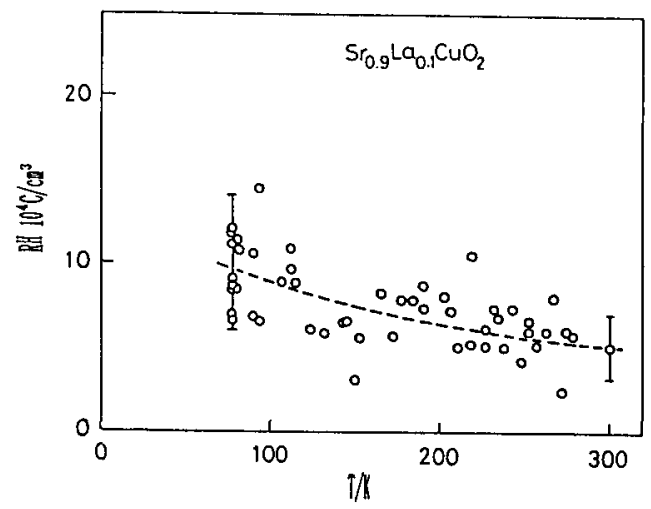

Fig. 5 Temperature dependence of llall coefficient for $\mathrm{Sr}_{0}, \mathrm{aLa}_{0}, \mathrm{CuO}_{2}$. 